\title{
Synthesis and structures of two cobalt compounds of 2-amino-2-methyl-1-propanol
}

\author{
YONGJIE QIN, SHANSHAN YANG, LONG LIU, YUNING LIANG and ZILU CHEN* \\ State Key Laboratory for the Chemistry and Molecular Engineering of Medicinal Resources, School of \\ Chemistry and Pharmaceutical Sciences, Guangxi Normal University, Guilin 541004, P. R. China \\ Email: zlchen@mailbox.gxnu.edu.cn
}

MS received 9 July 2016; revised 24 October 2016; accepted 29 October 2016

\begin{abstract}
The reactions of 2-amino-2-methyl-1-propanol (MepH) with $\mathrm{Co}\left(\mathrm{ClO}_{4}\right)_{2} \cdot 6 \mathrm{H}_{2} \mathrm{O}$ in the presence of acetic acid gave $\left[\mathrm{Co}_{2}(\mathrm{Mep})_{3}(\mathrm{OAc})(\mathrm{MepH})\right]\left(\mathrm{ClO}_{4}\right)_{2} \cdot \mathrm{MepH}(\mathbf{1})$ and $\left[\mathrm{Co}_{4}^{\mathrm{III}} \mathrm{Co}_{2}^{\mathrm{II}}(\mathrm{Mep})_{8}\left(\mu_{3}-\mathrm{OH}\right)_{2}(\mathrm{OAc})_{4}\right]\left(\mathrm{ClO}_{4}\right)_{2}$. $2 \mathrm{EtOH} \cdot 2 \mathrm{H}_{2} \mathrm{O}(2)$. They were characterized by elemental analysis, IR and single crystal X-ray diffraction analysis. Compound 1 presents a dinuclear structure with its two Co atoms linked by two Mep ${ }^{-}$ligands and one acetate ligand. The two $\mathrm{Co}(\mathrm{II})$ and four $\mathrm{Co}(\mathrm{III})$ centers in $\mathbf{2}$ are held together by eight Mep ${ }^{-}$ligands, two $\mu_{3}-\mathrm{OH}^{-}$ions and four acetate ligands to form a hexanuclear skeleton which contains a defected face-shared dicubane core. Their discrete polynuclear units are further linked into double-layered and mono-layered two-dimensional H-bonded framework, respectively.
\end{abstract}

Keywords. Crystal structure; Cobalt; 2-amino-2-methyl-1-propanol.

\section{Introduction}

Polynuclear clusters are springing up in recent years due to their potential applications in various fields such as catalysis, magnetism and luminescence. ${ }^{1-7}$ One of the most fascinating challenges in this field is to design and construct some special aesthetic structures ${ }^{8-11}$ to satisfy aimed properties. As is well-known, the selection of appropriate ligands plays a vital role in the formation of targeted clusters. This includes two aspects. ${ }^{12,13}$ One aspect is to select the efficient linking groups which help to bridge metal ions, and the other one is to design applicable non-coordinating groups to control the growth of nuclearities in dimensionalities. As revealed in literature, the small and flexible polydentate ligands ${ }^{14-17}$ show much advantage in constructing targeted clusters. With the above-mentioned considerations in mind, we aimed to investigate the coordination chemistry of 2-amino-2-methyl-1-propanol (MepH), which has the alkoxide linking group and the simple non-coordinating group of methyl. We herein report one dinuclear compound $\left[\mathrm{Co}_{2}(\mathrm{Mep})_{3}(\mathrm{OAc})(\mathrm{MepH})\right]\left(\mathrm{ClO}_{4}\right)_{2}$. $\mathrm{MepH}(\mathbf{1})$ and one hexanuclear compound $\left[\mathrm{Co}_{4}^{\mathrm{III}} \mathrm{Co}_{2}^{\mathrm{II}}\right.$ $\left.(\mathrm{Mep})_{8}\left(\mu_{3}-\mathrm{OH}\right)_{2}(\mathrm{OAc})_{4}\right]\left(\mathrm{ClO}_{4}\right)_{2} \cdot 2 \mathrm{EtOH} \cdot 2 \mathrm{H}_{2} \mathrm{O}(\mathbf{2})$.

*For correspondence

\section{Experimental}

\subsection{Materials and instrumentation}

CAUTION: Perchlorate salts are potentially explosive and should be prepared in small quantities and handled with great care.

The reagents and solvents were commercially available and used as received without further purification. Elemental analyses $(\mathrm{C}, \mathrm{H}$ and $\mathrm{N})$ were performed using a Perkin-Elmer 2400II elemental analyzer. FT-IR spectra were recorded in the range $400-4000 \mathrm{~cm}^{-1}$ on a Nicolet 360 spectrophotometer using $\mathrm{KBr}$ pellets. Magnetic susceptibility measurements were performed on a Quantum Design MPMSXL-5 SQUID magnetometer.

\subsection{Synthesis of $\left[\mathrm{Co}_{2}(\mathrm{Mep})_{3}(\mathrm{OAc})(\mathrm{MepH})\right]\left(\mathrm{ClO}_{4}\right)_{2}$. $\mathrm{MepH}(\mathbf{1})$ and $\left[\mathrm{Co}_{4}^{\mathrm{III}} \mathrm{Co}_{2}^{\mathrm{II}}(\mathrm{Mep})_{8}\left(\mu_{3}-\mathrm{OH}\right)_{2}(\mathrm{OAc})_{4}\right]$ $\left(\mathrm{ClO}_{4}\right)_{2} \cdot 2 \mathrm{EtOH} \cdot 2 \mathrm{H}_{2} \mathrm{O}(2)$}

To a stirred solution of $\mathrm{Co}\left(\mathrm{ClO}_{4}\right)_{2} \cdot 6 \mathrm{H}_{2} \mathrm{O} \quad(0.0366 \mathrm{~g}$, $0.1 \mathrm{mmol})$ in absolute ethanol $(10 \mathrm{~mL})$ was added 2-amino2-methyl-1-propanol $(0.0178 \mathrm{~g}, 0.2 \mathrm{mmol})$ and acetic acid $(0.0060 \mathrm{~g}, 0.1 \mathrm{mmol})$. The resulting solution was stirred for $24 \mathrm{~h}$ at room temperature. After filtration, the obtained solution was left at ambient temperature for solvent evaporation. After two weeks, pale blue block crystals of compound $\mathbf{1}$ and green needle-like crystals of compound $\mathbf{2}$ were obtained. The crystals were collected, washed with ethanol and dried, giving compounds $\mathbf{1}$ and $\mathbf{2}$ in a yield of $0.0061 \mathrm{~g}$ (10.6\% 
based on $\left.\mathrm{Co}\left(\mathrm{ClO}_{4}\right)_{2} \cdot 6 \mathrm{H}_{2} \mathrm{O}\right)$ and $0.0086 \mathrm{~g}(15.0 \%$ based on $\left.\mathrm{Co}\left(\mathrm{ClO}_{4}\right)_{2} \cdot 6 \mathrm{H}_{2} \mathrm{O}\right)$, respectively. They are stable in ambient condition. Anal. Calcd (\%) for $\mathrm{C}_{22} \mathrm{H}_{55} \mathrm{Cl}_{2} \mathrm{Co}_{2} \mathrm{~N}_{5} \mathrm{O}_{15}$ (1): C $32.26, \mathrm{H}$ 6.72, N 8.55. Found (\%): C 32.51, H 6.52, N 8.35. IR (KBr pellet, $\mathrm{cm}^{-1}$ ): $3422 \mathrm{w}, 3297 \mathrm{~m}, 3251 \mathrm{~m}, 2968 \mathrm{w}$, 2883w, 1563s, 1427m, 1238w, 1179m, 785w, 704w, 633m, 559m. Anal. Calcd (\%) for $\mathrm{C}_{44} \mathrm{H}_{110} \mathrm{Cl}_{2} \mathrm{Co}_{6} \mathrm{~N}_{8} \mathrm{O}_{30}$ (2): $\mathrm{C}$ $31.88, \mathrm{H} 6.64, \mathrm{~N}$ 6.76. Found (\%): C 32.02, H 6.34, N 6.58. IR (KBr pellet, $\mathrm{cm}^{-1}$ ): $3423 \mathrm{w}, 3296 \mathrm{~m}, 3252 \mathrm{~m}, 2967 \mathrm{w}$, $2873 \mathrm{w}, 1556 \mathrm{~s}, 1448 \mathrm{~m}, 1390 \mathrm{w}, 1374 \mathrm{w}, 1231 \mathrm{w}, 1179 \mathrm{~m}$, 1090s, 1053w, 982w, 784w, 702w, 623m, 560m.

\section{$2.3 \quad X$-ray Crystallography}

Single-crystal X-ray diffraction data for compounds $\mathbf{1}$ and 2 were collected on a SuperNova CCD-based diffractometer equipped with graphite-monochromated Mo $\mathrm{K} \alpha$ radiation ( $\lambda=0.71073 \AA$ ) by $\omega$-scan at $298(2) \mathrm{K}$ for compound $\mathbf{1}$ and for compound $\mathbf{2}$ at 153(2) K. Absorption correction were applied by using the multi-scan program SADABS. ${ }^{18}$ The structure was solved by direct methods using SHELXS-97 program and refined by the full-matrix least-squares method on $F^{2}$ with the SHELXL-97 program $^{19}$ or the corresponding programs in the SHELXTL package..$^{20}$ All non-hydrogen atoms were refined with anisotropic thermal parameters. A summary of crystal data is presented in Table 1 . The selected bond lengths and angles are shown in Table 2. Hydrogen bonds are listed in Table 3.

\section{Results and Discussion}

The reactions of $\mathrm{Co}\left(\mathrm{ClO}_{4}\right)_{2} \cdot 6 \mathrm{H}_{2} \mathrm{O}$ with 2-amino-2methyl-1-propanol in absolute ethanol in the presence of acetic acid gave a dinuclear $\mathrm{Co}_{2}^{\mathrm{III}}$ complex (1) and a mixed-valence hexanuclear $\mathrm{Co}_{4}^{\mathrm{III}} \mathrm{Co}_{2}^{\mathrm{II}}$ complex (2) as shown in Scheme 1. The oxidation states of the Co atoms in the two complexes were confirmed by the corresponding $\mathrm{Co}-\mathrm{O} / \mathrm{N}$ bond lengths, charge balance considerations and the bond valence sum (BVS) calculations. ${ }^{21,22}$

\subsection{Crystal structure of $\left[\mathrm{Co}_{2}(\mathrm{Mep})_{3}(\mathrm{OAc})(\mathrm{MepH})\right]$ $\left(\mathrm{ClO}_{4}\right)_{2} \cdot \mathrm{MepH}(\mathbf{1})$}

The single crystal X-ray diffractional analysis reveals that compound $\mathbf{1}$ crystallizes in the triclinic space group $P \overline{1}$. The selected bond lengths and angles for $\mathbf{1}$ are given in Table 2. The asymmetric unit of $\mathbf{1}$ is composed of one $\left[\mathrm{Co}_{2}(\mathrm{Mep})_{3}(\mathrm{OAc})(\mathrm{MepH})\right]^{2+}$ cation, two $\mathrm{ClO}_{4}^{-}$ anions and one lattice $\mathrm{MepH}$ molecule (Figure 1). Three of the MepH molecules are deprotonated to serve as $\mathrm{Mep}^{-}$ligands in 1. As shown in Figure 1, both Co1 and $\mathrm{Co} 2$ in compound $\mathbf{1}$ adopt distorted octahedral geometries with a $\left[\mathrm{N}_{2} \mathrm{O}_{4}\right]$ environment ${ }^{23,24}$ due to the coordination of three $\mathrm{Mep}^{-}$ligands and one $\mathrm{OAc}^{-}$anion.

Table 1. Crystallographic data for compounds $\mathbf{1}$ and $\mathbf{2 .}$

\begin{tabular}{|c|c|c|}
\hline Complex & 1 & 2 \\
\hline Formula & $\mathrm{C}_{22} \mathrm{H}_{55} \mathrm{Cl}_{2} \mathrm{Co}_{2} \mathrm{~N}_{5} \mathrm{O}_{15}$ & $\mathrm{C}_{44} \mathrm{H}_{110} \mathrm{Cl}_{2} \mathrm{Co}_{6} \mathrm{~N}_{8} \mathrm{O}_{30}$ \\
\hline FW & 818.47 & 1655.88 \\
\hline$T / \mathrm{K}$ & $298(2)$ & 153(2) \\
\hline Crystal system & Triclinic & Monoclinic \\
\hline Space group & $P \overline{1}$ & $C 2 / \mathrm{m}$ \\
\hline$a / \AA$ & $10.3508(8)$ & 22.8164(11) \\
\hline b/ $\AA$ & $10.6815(8)$ & $13.3547(3)$ \\
\hline$c / \AA$ & $17.8122(11)$ & $16.4024(8)$ \\
\hline$\alpha /^{\circ}$ & $84.615(6)$ & 90 \\
\hline$\beta /{ }^{\circ}$ & 76.113(6) & 133.376(9) \\
\hline$\gamma /{ }^{\circ}$ & $68.107(7)$ & 90 \\
\hline$V / \AA^{3}$ & $1773.9(2)$ & $3632.8(6)$ \\
\hline$Z$ & 2 & 2 \\
\hline$D_{\mathrm{c}} / \mathrm{g} \mathrm{cm}^{-3}$ & 1.532 & 1.514 \\
\hline$\mu / \mathrm{mm}^{-1}$ & 1.156 & 1.493 \\
\hline$\theta$ range for data $/{ }^{\circ}$ & 2.99 to 26.00 & 3.05 to 25.01 \\
\hline Reflections collected & 14450 & 11521 \\
\hline$R_{\text {int }}$ & 0.0388 & 0.0231 \\
\hline Data/restraints/parameters & $6963 / 1 / 429$ & 3357 / 8 / 244 \\
\hline$R_{1}^{\mathrm{a}}(I>2 \sigma(I))$ & 0.0633 & 0.0311 \\
\hline$w R_{2}^{\mathrm{b}}(I>2 \sigma(I))$ & 0.1557 & 0.0790 \\
\hline$R_{1}^{\text {a }}$ (all data) & 0.0887 & 0.0333 \\
\hline$w R_{2}^{\mathrm{b}}$ (all data) & 0.1766 & 0.0807 \\
\hline Largest diff. Peak, hole / (e $\left.\AA^{-3}\right)$ & 1.460 and -0.664 & 1.111 and -0.962 \\
\hline
\end{tabular}


Table 2. Selected bond lengths $(\AA)$ and angles $\left(^{\circ}\right)$ for $\mathbf{1}$ and $\mathbf{2}$.

\begin{tabular}{|c|c|c|c|c|c|}
\hline \multicolumn{6}{|l|}{1} \\
\hline Co1-O3 & $1.861(3)$ & Co1-N1 & $1.947(4)$ & $\mathrm{Co} 2-\mathrm{O} 1$ & $1.922(3)$ \\
\hline Co1-O1 & $1.892(3)$ & Co1-N3 & $1.949(4)$ & $\mathrm{Co} 2-\mathrm{N} 4$ & $1.940(4)$ \\
\hline $\mathrm{Co} 1-\mathrm{O} 2$ & $1.923(3)$ & $\mathrm{Co} 2-\mathrm{O} 4$ & $1.876(3)$ & $\mathrm{Co} 2-\mathrm{O} 6$ & $1.945(3)$ \\
\hline Co1-O5 & $1.935(3)$ & $\mathrm{Co} 2-\mathrm{O} 2$ & $1.912(3)$ & $\mathrm{Co} 2-\mathrm{N} 2$ & $1.953(4)$ \\
\hline O3-Co1-O1 & $91.86(14)$ & O3-Co1-N3 & $85.92(15)$ & $\mathrm{O} 1-\mathrm{Co} 2-\mathrm{N} 4$ & $90.19(16)$ \\
\hline O3-Co1-O2 & $91.82(15)$ & $\mathrm{O} 1-\mathrm{Co} 1-\mathrm{N} 3$ & $177.43(15)$ & $\mathrm{O} 4-\mathrm{Co} 2-\mathrm{O} 6$ & $87.02(14)$ \\
\hline $\mathrm{O} 1-\mathrm{Co} 1-\mathrm{O} 2$ & 81.04(13) & $\mathrm{O} 2-\mathrm{Co} 1-\mathrm{N} 3$ & $97.73(16)$ & $\mathrm{O} 2-\mathrm{Co} 2-\mathrm{O} 6$ & $93.19(14)$ \\
\hline O3-Co1-O5 & $173.54(14)$ & O5-Co1-N3 & $88.44(15)$ & $\mathrm{O} 1-\mathrm{Co} 2-\mathrm{O} 6$ & $91.71(14)$ \\
\hline O1-Co1-O5 & $93.84(13)$ & N1-Co1-N3 & $95.88(17)$ & N4-Co2-O6 & $172.61(15)$ \\
\hline O2-Co1-O5 & $92.06(14)$ & $\mathrm{O} 4-\mathrm{Co} 2-\mathrm{O} 2$ & $177.99(14)$ & $\mathrm{O} 4-\mathrm{Co} 2-\mathrm{N} 2$ & $96.63(16)$ \\
\hline O3-Co1-N1 & $91.55(17)$ & $\mathrm{O} 4-\mathrm{Co} 2-\mathrm{O} 1$ & $97.47(14)$ & $\mathrm{O} 2-\mathrm{Co} 2-\mathrm{N} 2$ & $85.38(15)$ \\
\hline O1-Co1-N1 & $85.45(15)$ & $\mathrm{O} 2-\mathrm{Co} 2-\mathrm{O} 1$ & $80.53(13)$ & $\mathrm{O} 1-\mathrm{Co} 2-\mathrm{N} 2$ & $165.62(15)$ \\
\hline $\mathrm{O} 2-\mathrm{Co} 1-\mathrm{N} 1$ & $166.17(15)$ & $\mathrm{O} 4-\mathrm{Co} 2-\mathrm{N} 4$ & $85.65(16)$ & $\mathrm{N} 4-\mathrm{Co} 2-\mathrm{N} 2$ & $93.74(18)$ \\
\hline O5-Co1-N1 & $85.88(16)$ & $\mathrm{O} 2-\mathrm{Co} 2-\mathrm{N} 4$ & $94.17(15)$ & O6-Co2-N2 & $86.16(17)$ \\
\hline \multicolumn{6}{|l|}{2} \\
\hline Co1-O1 & $1.8833(16)$ & Co2-O1A & $2.0258(17)$ & Co3-O5 & $1.8844(17)$ \\
\hline $\mathrm{Co} 1-\mathrm{O} 2$ & $1.9273(14)$ & $\mathrm{Co} 2-\mathrm{O} 3$ & $2.055(3)$ & $\mathrm{Co} 3-\mathrm{O} 4$ & $1.926(3)$ \\
\hline \multirow[t]{2}{*}{ Co1-N1 } & $1.945(2)$ & $\mathrm{Co} 2-\mathrm{O} 5$ & $2.0955(17)$ & Co3-O6 & $1.927(3)$ \\
\hline & & $\mathrm{Co} 2-\mathrm{O} 2$ & $2.169(2)$ & $\mathrm{Co} 3-\mathrm{N} 2$ & $1.940(2)$ \\
\hline O1-Co1-O1A & $176.73(11)$ & $\mathrm{O} 1 \mathrm{~B}-\mathrm{Co} 2-\mathrm{O} 1 \mathrm{~A}$ & $98.77(10)$ & O5-Co3-O5C & $87.03(10)$ \\
\hline $\mathrm{O} 1-\mathrm{Co} 1-\mathrm{O} 2 \mathrm{~B}$ & $86.11(8)$ & $\mathrm{O} 1 \mathrm{~A}-\mathrm{Co} 2-\mathrm{O} 3$ & $96.91(7)$ & O5-Co3-O4 & $94.52(8)$ \\
\hline $\mathrm{O} 1-\mathrm{Co} 1-\mathrm{O} 2$ & $96.42(9)$ & $\mathrm{O} 1 \mathrm{~B}-\mathrm{Co} 2-\mathrm{O} 5$ & $91.16(7)$ & O5-Co3-O6 & $89.69(8)$ \\
\hline $\mathrm{O} 2 \mathrm{~B}-\mathrm{Co} 1-\mathrm{O} 2$ & $79.29(10)$ & $\mathrm{O} 1 \mathrm{~A}-\mathrm{Co} 2-\mathrm{O} 5$ & $163.78(7)$ & O4-Co3-O6 & $174.19(11)$ \\
\hline O1-Co1-N1 & $85.41(8)$ & $\mathrm{O} 3-\mathrm{Co} 2-\mathrm{O} 5$ & $94.58(8)$ & $\mathrm{O} 5-\mathrm{Co} 3-\mathrm{N} 2 \mathrm{C}$ & 173.69(9) \\
\hline $\mathrm{O} 1 \mathrm{~A}-\mathrm{Co} 1-\mathrm{N} 1$ & $92.44(8)$ & $\mathrm{O} 5 \mathrm{C}-\mathrm{Co} 2-\mathrm{O} 5$ & $76.51(9)$ & O5-Co3-N2 & $86.79(8)$ \\
\hline O2-Co1-N1 & $91.91(8)$ & $\mathrm{O} 1 \mathrm{~A}-\mathrm{Co} 2-\mathrm{O} 2$ & $76.57(6)$ & $\mathrm{O} 4-\mathrm{Co} 3-\mathrm{N} 2$ & 84.71(9) \\
\hline O2-Co1-N1A & 167.01(9) & $\mathrm{O} 3-\mathrm{Co} 2-\mathrm{O} 2$ & $169.75(10)$ & O6-Co3-N2 & $91.54(8)$ \\
\hline N1-Co1-N1A & $98.26(13)$ & $\mathrm{O} 5-\mathrm{Co} 2-\mathrm{O} 2$ & $93.47(7)$ & $\mathrm{N} 2 \mathrm{C}-\mathrm{Co} 3-\mathrm{N} 2$ & $99.36(13)$ \\
\hline
\end{tabular}

Table 3. Hydrogen bonds for $\mathbf{1}$ and $\mathbf{2}\left(\AA\right.$ and $\left.^{\circ}\right)$.

\begin{tabular}{|c|c|c|c|c|}
\hline \multicolumn{5}{|l|}{1} \\
\hline $\mathrm{D}-\mathrm{H} \cdots \mathrm{A}$ & $\mathrm{d}(\mathrm{D}-\mathrm{H})$ & $\mathrm{d}(\mathrm{H} \cdots \mathrm{A})$ & $d(D \cdots A)$ & $<(\mathrm{DHA})$ \\
\hline N1-H1D...O12 & 0.90 & 2.48 & $3.244(8)$ & 142.6 \\
\hline N2-H2B...O11A & 0.90 & 2.14 & $3.026(7)$ & 166.2 \\
\hline N3-H3E...O15B & 0.90 & 2.38 & $3.190(9)$ & 148.9 \\
\hline O4-H4D...N5C & 0.85 & 1.98 & $2.646(5)$ & 134.9 \\
\hline N4-H4E...O7 & 0.90 & 2.10 & $2.969(6)$ & 162.8 \\
\hline O7-H7...O3 & $0.849(10)$ & $1.77(3)$ & $2.582(5)$ & $159(8)$ \\
\hline N5-H5D...O9 & 0.89 & 2.05 & $2.937(7)$ & 174.4 \\
\hline \multicolumn{5}{|c|}{ Symmetry codes: A) $x-1, y+1, z$; B) $-x+1,-y+1,-z+1$; C) $x, y+1, z$} \\
\hline \multicolumn{5}{|l|}{2} \\
\hline N1-H1C...O8D & 0.92 & 2.38 & $3.168(3)$ & 143.9 \\
\hline N1-H1D...O5C & 0.92 & 2.53 & $3.279(3)$ & 138.5 \\
\hline $\mathrm{O} 2-\mathrm{H} 2 \ldots \mathrm{O} 11$ & 0.84 & 1.80 & $2.617(4)$ & 164.4 \\
\hline N2-H2A...O7 & 0.92 & 2.22 & $2.955(3)$ & 136.8 \\
\hline $\mathrm{O} 11-\mathrm{H} 111 \ldots \mathrm{O} 12 \mathrm{E}$ & 0.84 & 1.86 & $2.700(5)$ & 171.5 \\
\hline O11-H112...O6 & 0.85 & 1.86 & $2.703(4)$ & 178.2 \\
\hline O12-H12...O9 & 0.85 & 2.03 & $2.855(6)$ & 163.5 \\
\hline \multicolumn{5}{|c|}{ Symmetry codes: C) $x,-y, z$; D) $x,-y+1, z$; E) $-x+1 / 2,-y+1 / 2,-z+1$} \\
\hline
\end{tabular}

Two of the $\mathrm{Mep}^{-}$ligands adopt chelating:bridging coordination modes using its $\mathrm{N}$ and $\mathrm{O}$ atoms to chelate to one $\mathrm{Co}(\mathrm{III})$ ion with the $\mathrm{O}$ atom bridging another $\mathrm{Co}$ (III) atom at the same time. However, the other $\mathrm{Mep}^{-}$ ligand and the $\mathrm{MepH}$ ligand behave as chelating coordination modes. The $\mathrm{OAc}^{-}$anion acts as a syn:syn-bridge. The oxidation states of the Co atoms in $\mathbf{1}$ are assumed to be +3 based on the $\mathrm{Co}-\mathrm{O} / \mathrm{N}$ bond lengths, charge 

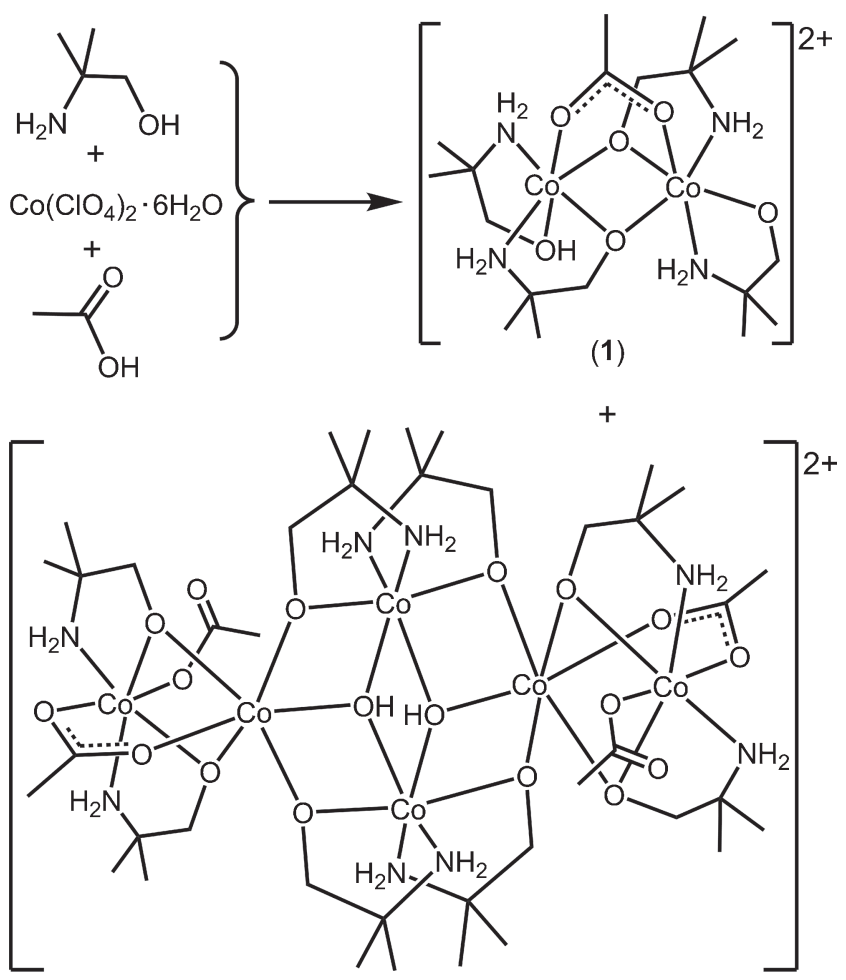

(2)

Scheme 1. Syntheses of $\mathbf{1}$ and 2.

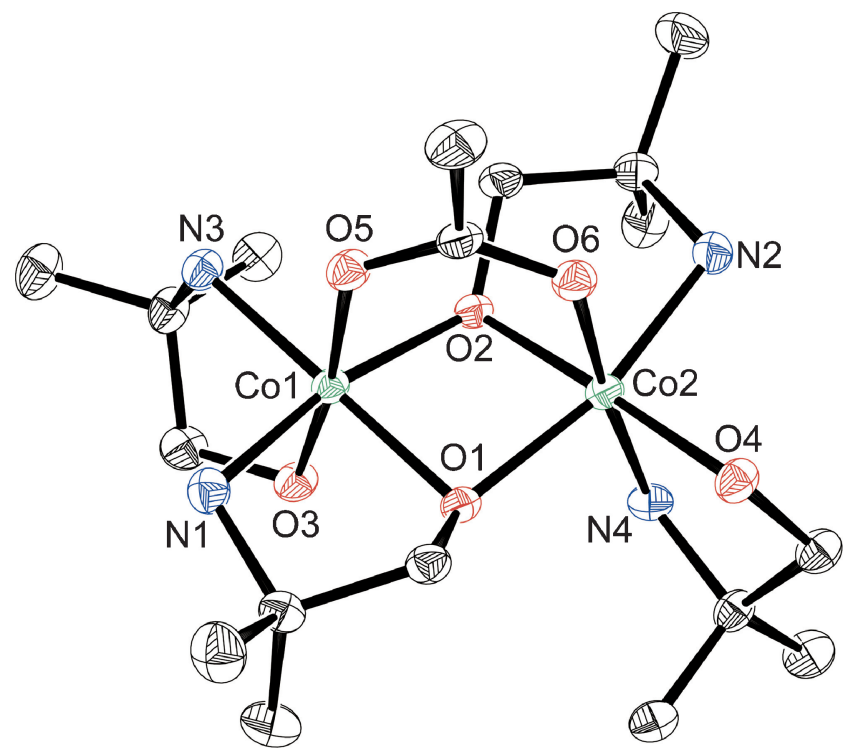

Figure 1. Molecular structure of $\mathbf{1}$ with selected atoms labeled and thermal ellipsoids drawn at $30 \%$ probability level. Hydrogen atoms are omitted for clarity.

balance consideration, and bond valence sum calculations (3.34 and 3.28 for $\mathrm{Co} 1$ and $\mathrm{Co} 2$, respectively). ${ }^{25}$ The Co-O bond lengths in $\mathbf{1}$ are in the range of 1.861(3)-1.945(3) $\AA$ (Table 2), which is similar to the reported $\mathrm{Co}(\mathrm{III})-\mathrm{O}$ bond length in literature. ${ }^{26} \mathrm{Co} 1$ and $\mathrm{Co} 2$ in $\mathbf{1}$ are connected by two chelating:bridging $\mathrm{Mep}^{-}$

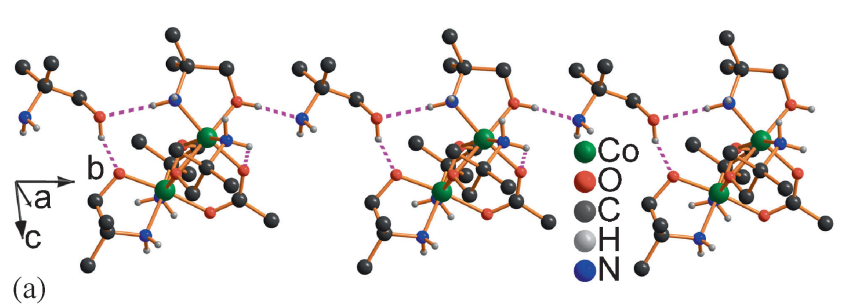

(a)

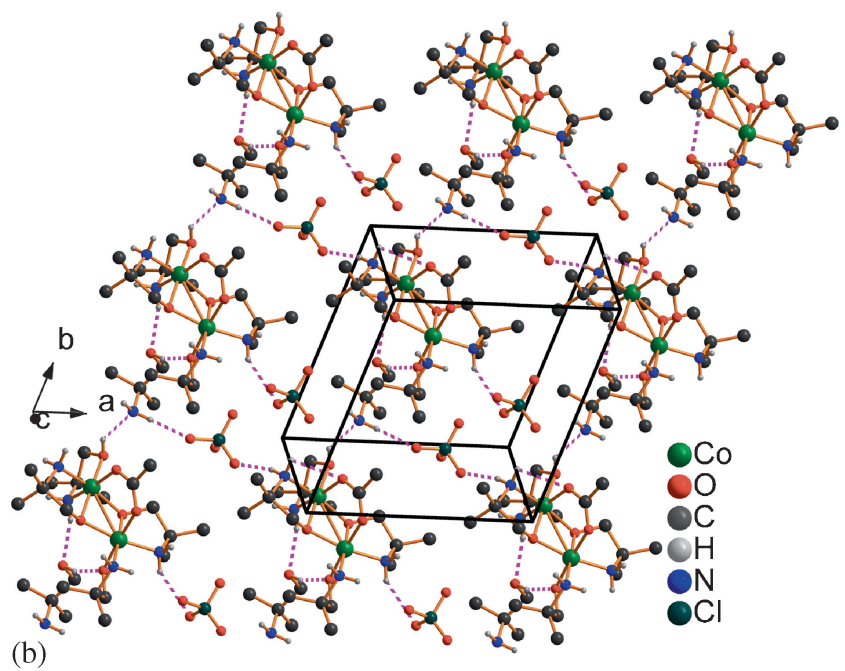

Figure 2. Pictures of the H-bonded chain (a), and the twodimensional H-bonded sheet (b) of $\mathbf{1}$. The dashed lines represent hydrogen bonds. The $\mathrm{C}$-bounded $\mathrm{H}$ atoms are omitted for clarity.

ligands and one syn:syn-bridging $\mathrm{OAc}^{-}$ligand, building the dinuclear skeleton of $\mathbf{1}$.

The neighboring dinuclear units along the $\mathrm{b}$ axis are linked by free MepH molecules through hydrogen bonds $\mathrm{O} 4 \cdots \mathrm{N} 5$ (symmetry code: $x, y+1, z$ ), O $\cdots \mathrm{O} 3$, and $\mathrm{N} 4 \cdots \mathrm{O} 7$ (Table 3), building one-dimensional $\mathrm{H}-$ bonded chains (Figure 2a). The free $\mathrm{ClO}_{4}^{-}$ions interact with the adjacent one-dimensional chains through hydrogen bonds $\mathrm{N} 5 \cdots \mathrm{O} 9$ and $\mathrm{N} 2 \cdots \mathrm{O} 11(x-1, y+$ $1, z$ ) (Table 3 ), resulting in the formation of a twodimensional $\mathrm{H}$-bonded sheet in the ab plane (Figure $2 b)$. Interestingly, two of such two-dimensional sheets are further connected by hydrogen bonds N3...O 15 $(-x+1,-y+14,-z+1)$ to form a double-layered $\mathrm{H}$-bonded structure as shown in Figure 3.

\subsection{Crystal structure of $\left[\mathrm{Co}_{4}^{I I I} \mathrm{Co}_{2}^{I I}(\mathrm{Mep})_{8}\left(\mu_{3}-\mathrm{OH}\right)_{2}\right.$} $(\mathrm{OAc})_{4} \mathrm{~J}\left(\mathrm{ClO}_{4}\right)_{2} \cdot 2 \mathrm{EtOH} \cdot 2 \mathrm{H}_{2} \mathrm{O}(2)$

Compound 2 crystallizes in the monoclinic space group $C 2 / \mathrm{m}$ (Figure 4). The selected bond lengths and angles for $\mathbf{2}$ are given in Table 2. As seen in Figure 2, $\mathbf{2}$ has an inversion center and consists of one $\left[\mathrm{Co}_{4}^{\mathrm{III}} \mathrm{Co}_{2}^{\mathrm{II}}(\mathrm{Mep})_{8}\right.$ $\left.\left(\mu_{2}-\mathrm{OH}\right)_{2}(\mathrm{OAc})_{4}\right]^{2+}$ cation, two $\mathrm{ClO}_{4}^{-}$anions, two lattice $\mathrm{EtOH}$ molecules and two lattice water molecules per formula unit. The eight $\mathrm{Mep}^{-}$ligands bridge Co 
centers in chelating:bridging modes. Two of the acetate ligands bridge two Co centers in a syn-syn bridging mode, while the other two acetate ligands behave as monodentate terminal ligands. Each Co ion is sixcoordinated in a distorted octahedral geometry. ${ }^{27} \mathrm{Co} 1$ is coordinated by two hydroxyl $\mathrm{O}$ atoms (O1 and O1B) and two amino $\mathrm{N}$ atoms (N1 and N1A) from two $\mathrm{Mep}^{-}$ ligands, and two $\mathrm{O}$ atoms $(\mathrm{O} 2$ and $\mathrm{O} 2 \mathrm{~A})$ from two $\mu_{3}-$ $\mathrm{OH}^{-}$ions with the Co1-N/O bond lengths varying in a range of 1.8833(16)-1.945(2) $\AA$ (Table 2). Co2 is coordinated by six $\mathrm{O}$ atoms from four $\mathrm{Mep}^{-}$ligands, one $\mathrm{OH}^{-}$anion and one $\mathrm{OAc}^{-}$anion. The Co2-O bond lengths are in the range of 2.0258(17)-2.169(2) $\AA^{28}$ The coordination atoms of $\mathrm{Co} 3$ are two $\mathrm{O}$ atoms (O5 and $\mathrm{O} 5 \mathrm{C}$ ) and two amino $\mathrm{N}$ atoms (N2 and $\mathrm{N} 2 \mathrm{C}$ ) from two $\mathrm{Mep}^{-}$ligands, and another two $\mathrm{O}$ atoms from two $\mathrm{OAc}^{-}$anions. The Co3-N/O bond lengths are in the

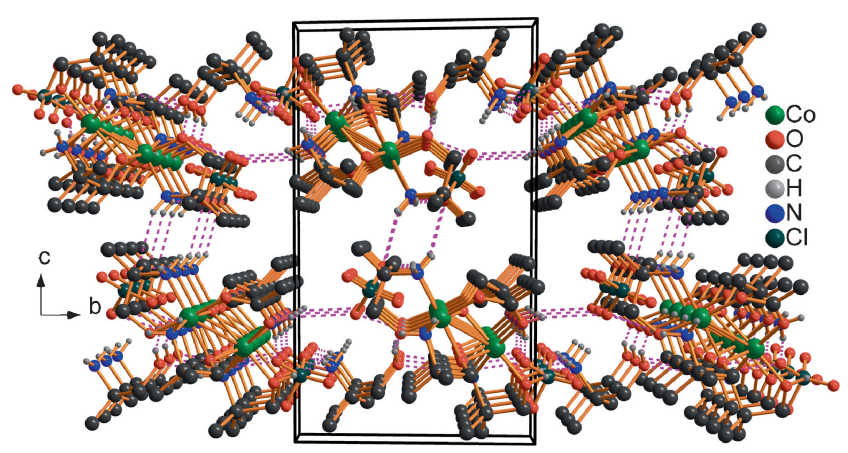

Figure 3. Double-layered H-bonded structure of 1. The dashed lines represent hydrogen bonds. The $\mathrm{C}$-bonded $\mathrm{H}$ atoms are omitted for clarity. range of 1.8844(17)-1.940(2) $\AA$. The bond valence sum calculations gave values of 3.33, 2.18 and 3.34 for Co1, $\mathrm{Co} 2$ and $\mathrm{Co} 3$ in complex 2 , respectively. These bond length information and the bond valence sum calculations reveal the oxidation state of +2 for $\mathrm{Co} 2$, and the oxidation state of +3 for $\mathrm{Co} 1$ and $\mathrm{Co} 3$, which are further confirmed by the charge balance. ${ }^{29} \mathrm{Co}$, $\mathrm{Co} 1 \mathrm{~A}, \mathrm{Co} 2$ and $\mathrm{Co} 2 \mathrm{~A}$ are consolidated by two $\mu_{3}-\mathrm{OH}^{-}$ ions and four alcoholic $\mathrm{O}$ atoms to form a face-sharing defected dicubane skeleton. Each unshared vertexes $(\mathrm{Co} 2$ and $\mathrm{Co} 2 \mathrm{~B})$ are further connected to another $\mathrm{Co}$ atom (Co3 and $\mathrm{Co} 3 \mathrm{~A})$, respectively, by two alcoholic oxygen atoms and one syn:syn-bridging $\mathrm{OAc}^{-}$anion. All of these connections lead to the construction of the hexanuclear structure of $\mathbf{2}$.

Every two adjacent hexanuclear units along the $\mathrm{b}$ axis are connected by two free $\mathrm{ClO}_{4}^{-}$anions through electrostatic interactions, as well as through hydrogen bonds N1 $\cdots$ O 8 $(x,-y+1, z)$ (Table 3$)$, leading to the formation of one-dimensional H-bonded chains (Figure 5). The neighboring one-dimensional H-bonded chains are linked by free ethanol and water molecules through $\mathrm{H}$ bonds $\mathrm{O} 2 \cdots \mathrm{O} 11, \mathrm{O} 11 \cdots \mathrm{O} 6, \mathrm{O} 11 \cdots \mathrm{O} 12(-x+1 / 2$, $-y+1 / 2,-z+1)$ and $\mathrm{O} 12 \cdots \mathrm{O} 9$ (Table 3 ), forming a two-dimensional H-bonded sheet as shown in Figure 5.

\subsection{Magnetic Property of 2}

Solid-state variable-temperature dc magnetic susceptibility measurements for $\mathbf{2}$ were carried out in an applied magnetic field of $1000 \mathrm{Oe}$ in the temperature range of

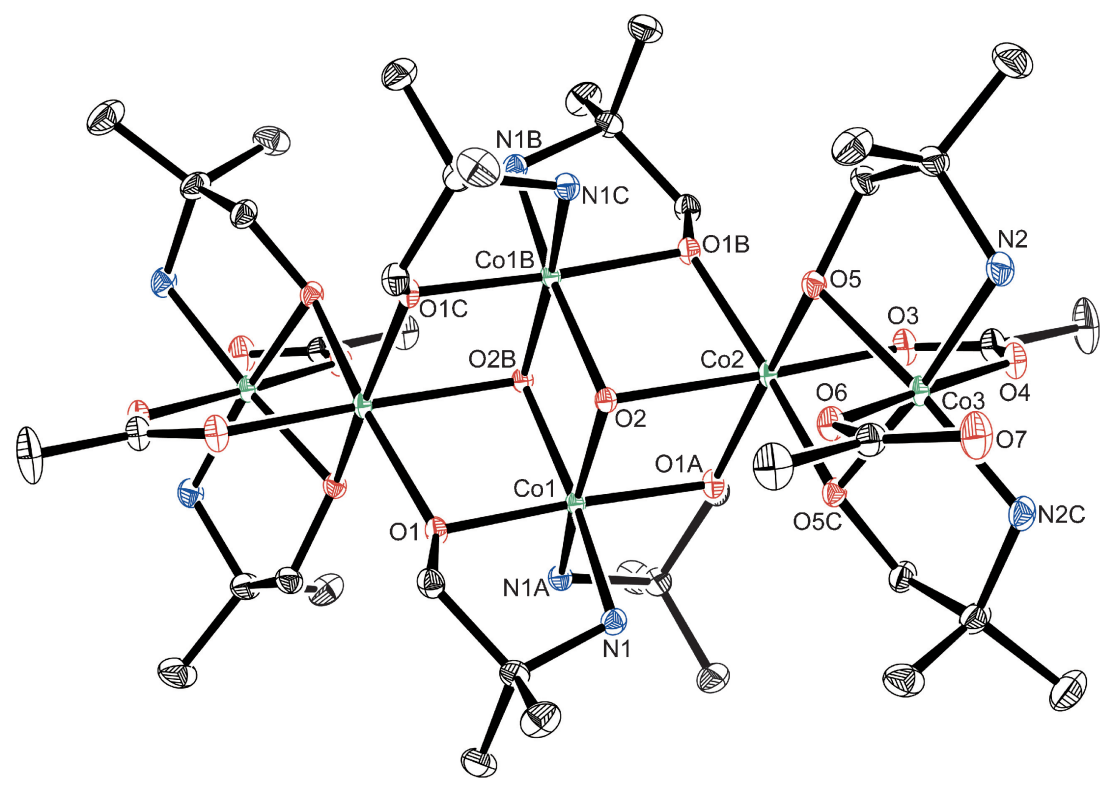

Figure 4. Molecular structure of 2 with selected atoms labeled. The thermal ellipsoids are drawn at $30 \%$ probability level. Hydrogen atoms are omitted for clarity. Symmetry codes: A) $-x, y,-z$; B) $-x,-y,-z$; C) $x,-y, z$. 


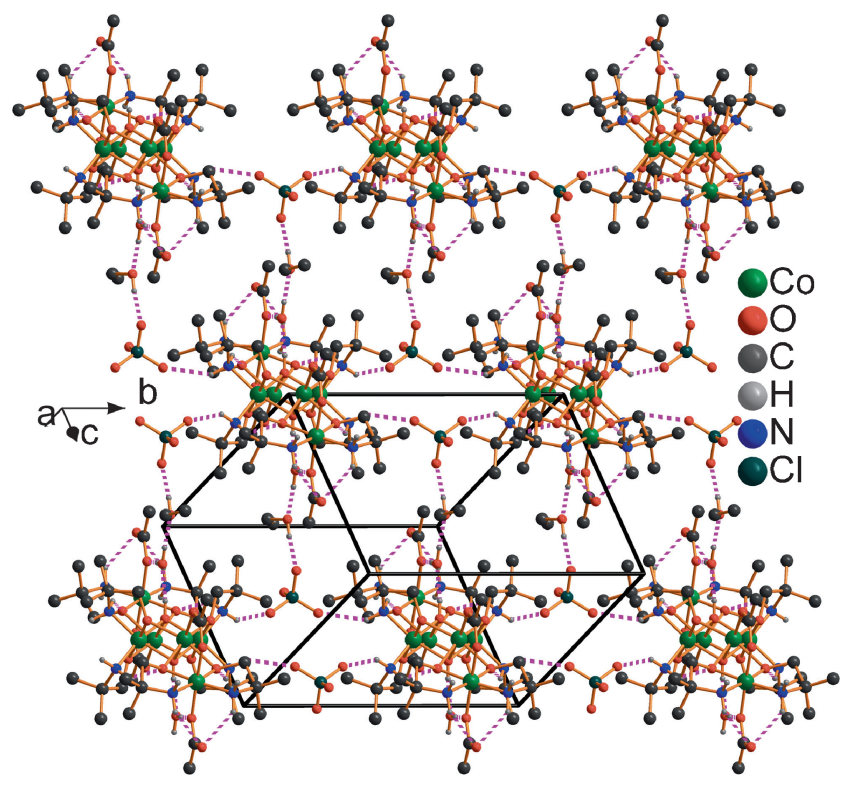

Figure 5. A picture of the two-dimensional H-bonded sheet of $\mathbf{2}$. The dashed lines represent hydrogen bonds. The C-bonded $\mathrm{H}$ atoms are omitted for clarity.

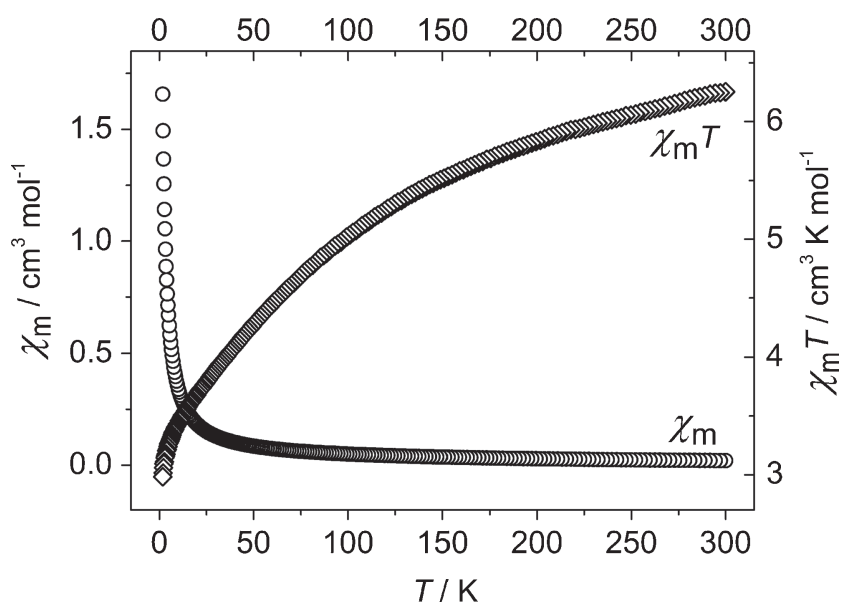

Figure 6. Plots of $\chi_{\mathrm{M}}$ and $\chi_{\mathrm{M}} T$ vs. $T$ of 2 at an applied field of 1000 Oe.

2-300 K. The plots of $\chi_{m}$ and $\chi_{\mathrm{m}} T$ vs. $T$ for 2 are shown in Figure 6. Its $\chi_{\mathrm{m}} T$ value of $6.25 \mathrm{~cm}^{3} \mathrm{~K} \mathrm{~mol}^{-1}$ at $300 \mathrm{~K}$ falls in the range $\left(4.2-6.8 \mathrm{~cm}^{3} \mathrm{~mol}^{-1}\right)$ for experimentally observed two highly anisotropic highspin $\mathrm{Co}$ (II) centers due to the largely unquenched orbital momentum of $\mathrm{Co}$ (II) ions. ${ }^{30}$ Upon cooling, the $\chi_{\mathrm{m}} T$ value decreases steadily to a minimum value of $3.0 \mathrm{~cm}^{3} \mathrm{~K} \mathrm{~mol}^{-1}$ at $2 \mathrm{~K}$. The profile of $\chi_{\mathrm{m}} T$ vs. $T$ curve for 2 is mainly due to the depopulation of crystal field splitting levels ${ }^{31}$ because the two $\mathrm{Co}$ (II) ions are well-separated.

\section{Conclusions}

An investigation of the coordination chemistry of 2-amino-2-methyl-1-propanol with $\mathrm{Co}$ (II) ions was carried out, which afforded one dinuclear cluster and one hexanuclear cluster. The hexanuclear cluster features a face-sharing defected dicubane skeleton with each of the two unshared vertexes further connected to another $\mathrm{Co}$ atom. The $\mathrm{Mep}^{-}$ligands in the dinuclear compound present two types of coordination modes of chelating and chelating:bridging, however, all $\mathrm{Mep}^{-}$ligands in the hexanuclear compound are in chelating:bridging coordination modes. The dinuclear units, free $\mathrm{MepH}$ and free $\mathrm{ClO}_{4}^{-}$ions in $\mathbf{1}$ are further consolidated by hydrogen bonds to form a double-layered two-dimensional H-bonded framework. The hexanuclear units in $\mathbf{2}$ are connected by free $\mathrm{ClO}_{4}^{-}$anions, free ethanol and water molecules through $\mathrm{H}$-bonds to build a mono-layered two-dimensional H-bonded sheet.

\section{Supplementary Information (SI)}

Crystallographic data for the two structures in this paper have been deposited in the Cambridge Crystallographic Database Center, CCDC, 12 Union Road, Cambridge CB21EZ, UK. Copies of the data can be obtained free of charge by quoting the depository number CCDC-1409594 for $\mathbf{1}$ and 1409595 for 2 (Fax:+44-1223-336-033; E-mail: deposit@ccdc.cam.ac.uk, http://www.ccdc.cam.ac.uk).

\section{Acknowledgements}

Authors gratefully thank the financial support by National Natural Foundation of China (grant no. 21261004), Guangxi Natural Science Foundation of China (grant no. 2013GXNSFGA019008 and 2013GXNSFAA019039), and Program for Excellent Talents in Guangxi Higher Education Institutions.

\section{References}

1. Chen Q, Zeng M-H, Wei L-Q and Kurmoo M 2010 A Multifaceted Cage Cluster, $\left[\mathrm{Co}_{6}^{\mathrm{II}} \mathrm{O}_{12} \supset \mathrm{X}\right]^{-}\left(\mathrm{X}=\mathrm{Cl}^{-}\right.$or $\mathrm{F}^{-}$): Halide Template Effect and Frustrated Magnetism Chem. Mater. 224328

2. Wang L, Li Y, Peng Y, Liang Z, Yu J and Xu R 2012 A novel decanuclear $\mathrm{Co}$ (II) cluster with adamantane-like metallic skeleton supported by 8-hydroxyquinoline and in situ formed $\mathrm{CO}_{3}^{2-}$ anions Dalton Trans. 416242

3. Galloway K W, Whyte A M, Wernsdorfer W, SanchezBenitez J, Kamenev K V, Parkin A, Peacock R D and Murrie M 2008 Cobalt(II) Citrate Cubane SingleMolecule Magnet Inorg. Chem. 477438

4. Li X, Cheng D, Lin J, Li Z and Zheng Y 2008 Di-, Tetra-, and Hexanuclear Hydroxy-Bridged Copper(II) Cluster Compounds: Syntheses, Structures, and Properties Cryst. Growth Des. 82853 
5. Tandon S S, Bunge S D, Rakosi R, Xu Z and Thompson L K 2009 Self-assembly of mixed-valence Co(II/III) and Ni(II) clusters: Azide-bridged 1D single chain coordination polymers comprised of tetranuclear units, tetranuclear Co(II/III) complexes, ferromagnetically coupled azide-bridged tetranuclear, and hexanuclear Ni(II) complexes: Synthesis, structural, and magnetic properties Dalton Trans. 6536

6. Nagarkar S S and Ghosh S K 2015 Reversible structural transformations in a $\mathrm{Co}(\mathrm{II})$-based $2 \mathrm{D}$ dynamic metalorganic framework showing selective solvent uptake $J$. Chem. Sci. 127627

7. Kilic A, Keles A, Aytar E, Durgun M and Ulusoy M 2015 Synthesis of the Multinuclear Cobaloxime Complexes via Click Chemistry as Catalysts for the Formation of Cyclic Carbonates from Carbon Dioxide and Epoxides J. Chem. Sci. 1271665

8. Chang W-K, Chiang R-K, Jiang Y-C, Wang S-L, Lee S-F and Lii K-H 2004 Metamagnetism in Cobalt Phosphates with Pillared Layer Structures: $\left[\mathrm{Co}_{3}(\mathrm{pyz})\left(\mathrm{HPO}_{4}\right)_{2} \mathrm{~F}_{2}\right]$ and $\left[\mathrm{Co}_{3}(4,4\right.$ '-bpy $\left.)\left(\mathrm{HPO}_{4}\right)_{2} \mathrm{~F}_{2}\right]$. $x \mathrm{H}_{2} \mathrm{O}$ Inorg. Chem. 432564

9. Zheng Y-Q, Lin J-L, Xu W, Xie H-Z, Sun J and Wang X-W 2008 A Family of New Glutarate Compounds: Synthesis, Crystal Structures of: $\mathrm{Co}\left(\mathrm{H}_{2} \mathrm{O}\right)_{5} \mathrm{~L}$ (1), $\mathrm{Na}_{2}\left[\mathrm{CoL}_{2}\right](2), \mathrm{Na}_{2}\left[\mathrm{~L}\left(\mathrm{H}_{2} \mathrm{~L}\right)_{4 / 2}\right](3),\left\{\left[\mathrm{Co}_{3}\left(\mathrm{H}_{2} \mathrm{O}\right)_{6} \mathrm{~L}_{2}\right]\right.$ $\left.(\mathrm{HL})_{2}\right\} \cdot 4 \mathrm{H}_{2} \mathrm{O}(4),\left\{\left[\mathrm{Co}_{3}\left(\mathrm{H}_{2} \mathrm{O}\right)_{6} \mathrm{~L}_{2}\right](\mathrm{HL})_{2}\right\} \cdot 10 \mathrm{H}_{2} \mathrm{O}(\mathbf{5})$, $\left\{\left[\mathrm{Co}_{3}\left(\mathrm{H}_{2} \mathrm{O}\right)_{6} \mathrm{~L}_{2}\right] \mathrm{L}_{2 / 2}\right\} \cdot 4 \mathrm{H}_{2} \mathrm{O}(\mathbf{6})$, and $\mathrm{Na}_{2}\left\{\left[\mathrm{Co}_{3}\left(\mathrm{H}_{2} \mathrm{O}\right)_{2}\right]\right.$ $\left.\mathrm{L}_{8 / 2}\right] \cdot 6 \mathrm{H}_{2} \mathrm{O}(7)$, and Magnetic Properties of $\mathbf{1}$ and $\mathbf{2}$ with $\mathrm{H}_{2} \mathrm{~L}=\mathrm{HOOC}-\left(\mathrm{CH}_{2}\right)_{3}-\mathrm{COOH}$ Inorg. Chem. 4710280

10. Wang S, Bi Y and Liao W 2015 Constructing calixarenesupported high nuclearity $\mathrm{Co}_{27}, \mathrm{Co}_{28}$ and $\mathrm{Ni}_{18} \mathrm{Na}_{6}$ clusters with triazoles as co-bridges CrystEngComm 17 2896

11. Dolai M and Ali M 2014 Two new twisted helical nickel(II) and cobalt(III) octahedral monomer complexes: Synthesis and structural characterization J. Chem. Sci. 1261647

12. Aguila D, Barrios L A, Roubeau O, Teat S J and Aromi G 2011 Molecular assembly of two $\left[\mathrm{Co}(\mathrm{II})_{4}\right]$ linear arrays Chem. Commun. 47707

13. Ali A, Bansal D and Gupta R 2014 Synthesis, characterization and self-assembly of $\mathrm{Co}^{3+}$ complexes appended with phenol and catechol groups J. Chem. Sci. 1261535

14. Kapanadze T S, Gorbunova Y E, Kokunov Y V and Buslaev Y A 1991 Stereochemistry of Cobalt(III) Complexes Containing (N,O)-Five and Six-membered Aminoalcohol Chelate Rings Mendeleev Commun. 155

15. Alley K G, Bircher R, Waldmann O, Ochsenbein S T, Güdel H U, Moubaraki B, Murray K S, FernandezAlonso F, Abrahams B F and Boskovic C 2006 MixedValent Cobalt Spin Clusters: A Hexanuclear Complex and a One-Dimensional Coordination Polymer Comprised of Alternating Hepta- and Mononuclear Fragments Inorg. Chem. 458950

16. Alley K G, Mukherjee A, Clérac R and Boskovic C 2008 A new family of octanuclear $\mathrm{Cu}_{4} \mathrm{Ln}_{4}(\mathrm{Ln}=\mathrm{Gd}, \mathrm{Tb}$ and Dy) spin clusters Dalton Trans. 59
17. Manoli M, Collins A, Parsons S, Candini A, Evangelisti M and Brechin E K 2008 Mixed-Valent Mn Supertetrahedra and Planar Discs as Enhanced Magnetic Coolers J. Am. Chem. Soc. 13011129

18. Sheldrick G M 2002 SADABS:Version version 2.05, University of Göttingen, Göttingen, Germany

19. Sheldrick G M 2008 A short history of SHELX Acta Cryst. A64 112

20. Sheldrick G M 1997 SHELXTL NT:Version version 5.1, University of Göttingen, Göttingen, Germany

21. Urusov V S 1995 Semi-Empirical Groundwork of the Bond-Valence Model Acta Cryst. B51 641

22. Palenik G J 1997 Bond Valence Sums in Coordination Chemistry Using Oxidation State Independent R0 Values Inorg. Chem. 36122

23. Langley $\mathrm{S}$ K, Helliwell M, Teat S J and Winpenny R E P 2012 Synthesis and characterisation of cobalt(II) phosphonate cage complexes utilizing carboxylates and pyridonates as co-ligands Dalton Trans. 4112807

24. He Y-C, Zhang X, Liu Y-Y, Liu H-Y and Ma J-F 2014 Four Cobalt(II)-Containing Coordination Polymers: Effects of $\mathrm{pH}$ Value and Temperature on Synthesis, Gas-Sorption, and Magnetic Properties Eur. J. Inorg. Chem. 20146205

25. Peng Y, Tian $\mathrm{C} \mathrm{B}$, Zhang $\mathrm{H} \mathrm{B}, \mathrm{Li} \mathrm{Z} \mathrm{H}$, Lin $\mathrm{P}$ and Du S W 2012 Synthesis, structure and magnetic study of a novel mixed-valent $\mathrm{Co}_{10}^{\mathrm{II}} \mathrm{Co}_{4}^{\mathrm{III}}$ shield constructed by mixed pyridine-alcoholate ligands Dalton Trans. 41 4740

26. Huang W-J, Hsu C-J, Tsai S-K, He H-Y, Ding J-J, Hsu T-W, Yang C-C and Chen J-D 2015 Homo- and heterometallic coordination networks based on linear trinuclear $\mathrm{Co}(\mathrm{II})$ units: Syntheses, structures and magnetic properties $R S C A d v .523374$

27. Ferguson A, Schmidtmann M, Brechin E K and Murrie M 2011 Bis-tris propane as a new multidentate ligand for nickel- and cobalt-based spin clusters Dalton Trans. 40334

28. Lisnard L, Mialane P, Dolbecq A, Marrot J, ClementeJuan J M, Coronado E, Keita B, de Oliveira P, Nadjo L and Sécheresse F 2007 Effect of Cyanato, Azido, Carboxylato, and Carbonato Ligands on the Formation of Cobalt(II) Polyoxometalates: Characterization, Magnetic, and Electrochemical Studies of Multinuclear Cobalt Clusters Chem. Eur. J. 133525

29. Ferguson A, Parkin A, Sanchez-Benitez J, Kamenev K, Wernsdorfer W and Murrie M 2007 A mixed-valence $\mathrm{Co}_{7}$ single-molecule magnet with $C_{3}$ symmetry Chem. Commun. 3473

30. Wu D, Zhang X, Huang P, Huang W, Ruan M and Ouyang Z W 2013 Tuning Transverse Anisotropy in Co ${ }^{\mathrm{III}}-\mathrm{Co}^{\mathrm{II}}-\mathrm{Co}^{\mathrm{III}}$ Mixed-Valence Complex toward Slow Magnetic Relaxation Inorg. Chem. 5210976

31. Zhu Y-Y, Zhang Y-Q, Yin T-T, Gao C, Wang B-W and Gao S 2015 A Family of $\mathrm{Co}^{\mathrm{II}} \mathrm{Co}_{3}^{\mathrm{III}}$ Single-Ion Magnets with Zero-Field Slow Magnetic Relaxation: Fine Tuning of Energy Barrier by Remote Substituent and Counter Cation Inorg. Chem. 545475 